\title{
DESEMPENHO DA SONDA DE DISSIPAÇÃO TÉRMICA NA MEDIDA DA TRANSPIRAÇÃO DE PLANTAS JOVENS DE LIMA ÁCIDA ${ }^{1}$
}

\section{JUAN S. DELGADO-ROJAS ${ }^{2}$, LUIZ R. ANGELOCCI ${ }^{3}$, MARCOS V. FOLEGATTI ${ }^{4}$, MAURÍCIO A. COELHO FILHO}

\begin{abstract}
RESUMO: Devido à dificuldade de se quantificar o consumo individual de água de uma árvore, tem surgido uma série de técnicas de medida do fluxo de seiva que passa por meio do caule, o qual é relacionado diretamente com a transpiração da planta. Este trabalho teve como objetivo avaliar o desempenho de uma dessas técnicas, denominada método da sonda de dissipação térmica (SDT), na medida de fluxo de seiva em plantas de lima ácida 'Tahiti'. O experimento foi instalado em pomar de plantas jovens, localizado na fazenda experimental de irrigação, do Departamento de Engenharia Rural da ESALQ, em Piracicaba - SP, sendo a avaliação feita utilizando dois lisímetros de pesagem. Os resultados indicaram que o método estudado pode ser utilizado para essa finalidade em condições de campo; no entanto, a exatidão de suas medidas depende de certos conceitos teóricos que devem ser considerados e de certas correções que devem ser realizadas. Essas considerações, assim como as vantagens e desvantagens desse método, são discutidas neste trabalho.
\end{abstract}

PALAVRAS-CHAVE: citros, fluxo de seiva, sonda de Granier.

\section{PERFORMANCE OF THERMAL DISSIPATION PROBE IN THE MEASUREMENT OF TRANSPIRATION OF YOUNG PLANT OF 'TAHITI' ACID LIME}

\begin{abstract}
Because of the difficulty to quantify water consumption of a single tree, for irrigation scheduling, a series of techniques has appeared that directly measure the sap flow through the stem which can be related directly to transpiration. The objective of this work was to evaluate the performance of one of these methods, called heat dissipation probe method (HDP), in the measurement of sap flow using 'Tahiti' lemon trees. Experiments were installed in an orchard of young trees, located in the experimental farm of irrigation of ESALQ, in Piracicaba, São Paulo State, Brazil. The evaluation was carried out using two weight lysimeters. The results demonstrated that the method can be used to measure the transpiration in citrus; however, the accuracy depends on theoretical concepts that should be considered and of certain corrections that should be accomplished. Those considerations as well as the advantages and disadvantages of this method are discussed in this work.
\end{abstract}

KEYWORDS: citrus, sap flow, Granier probe.

\footnotetext{
${ }^{1}$ Trabalho financiado pela Fundação de Amparo à Pesquisa do Estado de São Paulo (FAPESP).

${ }^{2}$ Eng $^{\circ}$ Agrônomo, Doutor em Irrigação e Drenagem, Pós-doutorando, Departamento de Engenharia Rural, ESALQ/USP, Piracicaba - SP, Fone: (0XX19) 3432.7429, jsdrojas@ esalq.usp.br, Bolsista do CNPq.

${ }^{3}$ Engo ${ }^{o}$ Agrônomo, Prof. Doutor, Departamento de Ciências Exatas, ESALQ/USP, Piracicaba - SP, Bolsista do CNPq.

${ }^{4}$ Eng $^{\mathrm{o}}$ Agrônomo, Prof. Doutor, Departamento de Engenharia Rural, ESALQ/USP, Piracicaba - SP, Bolsista do CNPq.

${ }^{5}$ Engo ${ }^{0}$ Agrônomo, Doutor em Irrigação e Drenagem, Pesquisador da EMBRAPA Mandioca e Fruticultura, Cruz das Almas - BA.

Recebido pelo Conselho Editorial em: 2-5-2006

Aprovado pelo Conselho Editorial em: 5-6-2007
} 


\section{INTRODUÇÃO}

Para aplicação eficiente da água na irrigação, é indispensável dispor de informações sobre as condições hídricas do solo e da evapotraspiração da cultura. Em culturas perenes, formando um pomar, com grande espaçamento entre árvores, no qual a planta é considerada "isolada", um problema é determinar o volume de água a ser aplicado por planta em cada período de tempo, pois, apesar dos numerosos trabalhos realizados, não se tem um método prático e confiável de medida da transpiração que possa ser utilizado em condições de campo sem incorrer em grandes erros.

Nas últimas duas décadas, vêm sendo testadas algumas técnicas conhecidas como "métodos térmicos" que, apesar da complexidade envolvida, vêm demonstrando bons resultados. Esses métodos utilizam fornecimento de calor ao caule, atuando como "marcador" da seiva, o qual pode ser relacionado com a densidade de fluxo de seiva e, por conseqüência, com a transpiração.

Entre eles, o método denominado de "sonda de dissipação térmica" (SDT) ou sonda de Granier, proposto originalmente por GRANIER (1985), tem sido indicado para uso em lenhosas e vem sendo empregado por vários autores (GRANIER, 1987; FERREIRA \& ZITSCHER, 1996; GRANIER \& BRÉDA, 1996; LOUSTAU et al., 1998; TOURNEBIZE \& BOISTARD, 1998; NAVES-BARBIERO et al., 2000; BURGESS et al., 2001; LUNDBLAD et al., 2001; LU et al., 2002; HUBBARD et al., 2004; TATARINOV et al., 2005), demonstrando ser alternativa promissora na medida da transpiração em plantas arbóreas. O SDT utiliza princípios físicos relativamente simples e pode ser aplicado diretamente no campo, sem alterar as condições fisiológicas e microclimáticas da planta. Comparado com os outros dois métodos térmicos, mais comumente usados, o de pulso de calor (COHEN et al., 1981; GREEN \& CLOTHIER, 1988; KÖSTNER et al., 1998; GIORIO \& GIORIO, 2003) e o de balanço de calor no caule (CERMÁK et al., 1973; SAKURATANI, 1981; STEINBERG et al., 1989; BAKER \& NIEBER, 1989; ANGELOCCI \& VALANCOGNE, 1993), é o método mais simples quanto à instrumentação utilizada, além de apresentar facilidade de confecção e instalação da sonda, bem como versatilidade quanto à adaptação para qualquer planta lenhosa, com diâmetro de caule acima de $4 \mathrm{~cm}$ (SMITH \& ALLEN, 1996).

As vantagens mencionadas podem permitir que esse método seja utilizado futuramente na prática do planejamento e do manejo da irrigação. Para isso, será necessário torná-lo mais simples, pois, devido à necessidade de registrar numerosos valores térmicos em intervalos de tempo, demandando um sistema de aquisição e tratamento de dados por meio de microprocessadores, seu uso ainda é considerado problemático fora do ambiente acadêmico. Portanto, há necessidade de estudá-lo mais profundamente, principalmente no que diz respeito a sua calibração para cada espécie de planta estudada, assim como a maneira de minimizar os potenciais erros mencionados na literatura.

Autores como CABIBEL \& DO (1991), FERREIRA \& ZITSCHER (1996), LUNDBLAD et al. (2001) e DO \& ROCHETEAU (2002) têm constatado que uma das principais fontes de erros dessa técnica é a interferência na medida do gradiente térmico natural do caule (GTN), ocasionada pela influência da carga térmica radiante e da temperatura do ar sobre o caule. Devido ao fato de o calor dissipado pela sonda térmica, inserida no caule, ser muito baixo, da ordem de 0,2 watt, qualquer gradiente natural de temperatura nesse órgão pode interferir significativamente sobre a estimativa de fluxo de seiva. Segundo DO \& ROCHETEAU (2002), a influência do GTN depende muito das condições nas quais se realizam as medidas. Ela pode ainda ser acentuada pela baixa densidade das árvores, alta intensidade da radiação solar e baixa taxa de fluxo de seiva.

O trabalho teve como objetivo avaliar o desempenho do método da SDT na determinação do fluxo de seiva em lima ácida 'Tahiti' e quantificar a interferência do GTN sobre as medidas do fluxo. 


\section{MATERIAL E MÉTODOS}

O experimento foi conduzido entre agosto e setembro de 2002, em pomar de plantas jovens de lima ácida 'Tahiti' (Citrus latifolia T.), copas do clone IAC 5, enxertadas em citrumelo 'Swingle', transplantadas com espaçamento de $7 \mathrm{~m} \mathrm{x} 4 \mathrm{~m}$, em junho de 2001, e irrigadas por meio de gotejadores. O pomar está localizado na área experimental de irrigação (Fazenda Areão), do Departamento de Engenharia Rural, da Escola Superior de Agricultura "Luiz de Queiroz" (ESALQ - USP), Piracicaba - SP, nas seguintes coordenadas geográficas: latitude: 2241'39''S, longitude: $47^{\circ} 38^{\prime} 16^{\prime}$ 'W e altitude: $546 \mathrm{~m}$.

Foram utilizadas quatro plantas, duas das quais transplantadas em lisímetros de pesagem, que utilizam como elemento sensor três células de carga cada um, da marca Ohmega, Inc., com tanques internos em aço-carbono e dimensões de $80 \mathrm{~cm}$ de diâmetro por $60 \mathrm{~cm}$ de profundidade e $160 \mathrm{~cm}$ de diâmetro por $60 \mathrm{~cm}$ de profundidade, respectivamente. Detalhes sobre a calibração e a confiabilidade dos lisímetros utilizados se encontram em CAMPECHE et al. (2002). Essas duas plantas - Planta 1, com área foliar de $1,78 \mathrm{~m}^{2}$, e Planta 2, com área foliar de 3,12 $\mathrm{m}^{2}$ - foram empregadas para medir a transpiração por variação de peso, dada por lisímetro, e por meio do fluxo de seiva, pelo método da SDT. As outras duas plantas, com tamanhos similares, foram utilizadas para medir o gradiente térmico natural (GTN) no caule por meio de sondas de Granier sem aquecimento.

A área foliar foi determinada diretamente, multiplicando o número total de folhas pela área média das mesmas. A área média das folhas foi determinada multiplicando-se os valores médios do comprimento máximo pela média da largura máxima de 200 folhas, tomadas de forma aleatória da planta em estudo. Esse resultado foi multiplicado por um fator de ajuste igual a 0,71, obtido em trabalho preliminar (DELGADO-ROJAS, 2003). A transpiração foi medida cobrindo o solo do lisímetro com lona plástica que, por sua vez, foi coberta com lâmina refletora para minimizar o aquecimento do solo, deixando livre apenas a parte aérea da planta.

O fluxo de seiva foi relacionado com a transpiração por meio de análise de regressão, para dados diários, e por comparação das curvas de variação no tempo, para valores de 20 minutos. Foi analisada, também, a coerência das estimativas, observando-se os resultados das medidas em relação ao tamanho das plantas e a tendência da taxa de fluxo de seiva com relação à transpiração e à demanda evaporativa do ar.

Como variável de acompanhamento da demanda evaporativa do ar, foi determinada diariamente a evapotranspiração de referência, pelo método de Penman-Monteith, de acordo com a parametrização proposta pela FAO (ALLEN et al., 1998), a partir dos dados meteorológicos registrados na estação agrometeorológica automática, situada a $50 \mathrm{~m}$ do pomar. Os sinais gerados pelos sensores de elementos meteorológicos foram registrados por meio de sistema de aquisição automática de dados (Campbell Scientific. Inc., modelo CR10X), com freqüência de aquisição de sinal de um segundo e armazenamento do valor médio na memória do sistema a cada 20 minutos. Os sistemas de aquisição de dados utilizados para registrar, com a mesma freqüência e intervalo de armazenamento, os valores gerados pelas sondas de Granier e pelas células de carga foram da mesma marca, sendo os modelos CR10X e CR23X, respectivamente.

\section{Confecção, instalação e princípios de funcionamento dos sensores de fluxo de seiva}

Os sensores foram confeccionados, conforme descrito por GRANIER (1985).

O método da sonda de SDT consiste na determinação da densidade de transporte convectivo de massa (seiva) a partir da taxa de dissipação de calor ocasionado pelo transporte.

O sistema de medida envolve a inserção perpendicular na mesma linha axial no tronco, caule ou ramo, de duas sondas térmicas distanciadas $5 \mathrm{~cm}$ entre si, sendo a sonda inferior inserida a $5 \mathrm{~cm}$ do solo. Cada sonda é constituída de uma agulha hipodérmica de $10 \mathrm{~mm}$ de comprimento e $2 \mathrm{~mm}$ de diâmetro, dentro da qual é inserida uma junção de termopar de cobre-constantan para medida da variação térmica no interior do lenho. 
É importante esclarecer que a sonda original descrita por GRANIER (1985) tinha $20 \mathrm{~mm}$ de comprimento, mas, neste caso, devido ao pequeno diâmetro dos caules das plantas envolvidas no experimento, foram utilizadas sondas de $10 \mathrm{~mm}$ de comprimento.

Os termopares das duas sondas são ligados em série de forma a ter a diferença de temperatura entre ambos os pontos de inserção (Figura 1). Uma das sondas é envolvida com fio de constantan (diâmetro de $50 \mu \mathrm{m}$ ), formando uma resistência dissipadora de calor, por meio da aplicação contínua de potência elétrica de 0,1 watt, através de uma fonte de tensão estabilizada.

GRANIER (1985) recomenda dissipar 0,2 watt de calor quando é utilizada sonda de $20 \mathrm{~mm}$ de comprimento; no entanto, utilizando-se de sonda de $10 \mathrm{~mm}$, foi fornecido metade do valor recomendado. A segunda sonda, colocada abaixo da sonda aquecida, não tem o fio resistor e serve para monitorar as variações térmicas naturais do tronco, as quais participam da variação do regime térmico do tronco. Na instalação, as sondas são inseridas no caule, dentro de uma cápsula de alumínio, para não ter contato direto com a seiva. Previamente, essa cápsula é preenchida com uma pasta térmica, dissipadora de calor, para melhorar o contato das sondas e uniformizar a temperatura ao longo delas. A variação da diferença de temperatura entre a sonda aquecida e a não-aquecida, observada ao longo do dia, deve-se ao transporte convectivo de calor por meio da seiva; portanto, a máxima diferença entre os dois pontos $(\Delta \mathrm{TM})$ ocorre quando o fluxo de seiva é mínimo ou nulo, enquanto a mínima diferença ocorre quando a taxa é máxima.

Na Figura 1, são apresentados detalhes da instalação do sensor. Maiores informações sobre a confecção da sonda e de sua instalação são encontradas em DELGADO-ROJAS (2003).

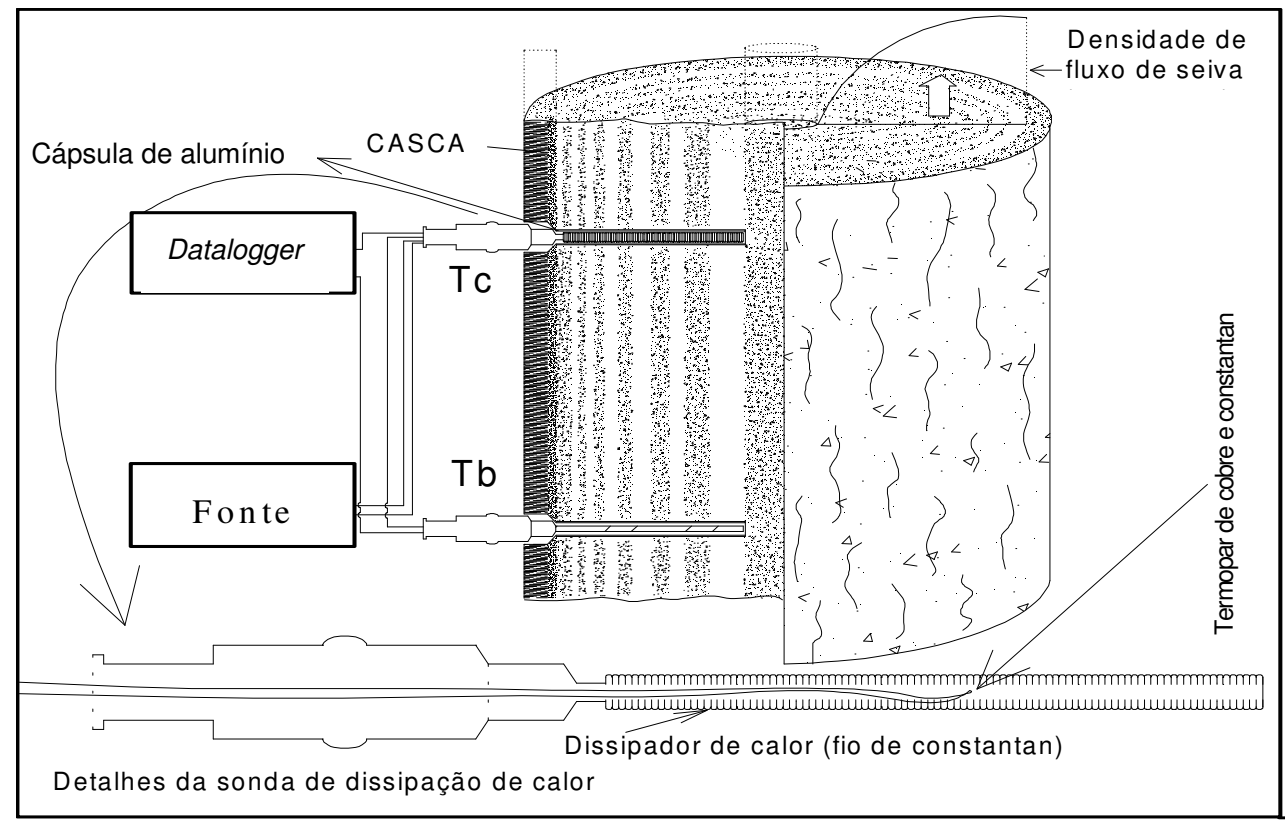

FIGURA 1. Detalhes do sensor de Granier instalado no tronco de uma árvore. Na parte inferior da figura, observam-se os detalhes da sonda aquecida.

$\mathrm{Na}$ determinação do fluxo de seiva $\left(\mathrm{F}, \mathrm{em} \mathrm{m}^{3} \mathrm{~s}^{-1}\right)$, foi utilizado o procedimento descrito por GRANIER (1985), que propôs a seguinte relação:

$$
\text { F - } 118,9910^{-6} \mathrm{~K}^{1,231} \mathrm{AS}
$$

em que,

AS - área condutora da seiva bruta $\left(\mathrm{m}^{2}\right)=$ área ocupada pelo xilema, e

$\mathrm{K}$ - fator característico calculado pela eq.(2). 
$\mathrm{K}-(\Delta \mathrm{TM}-\Delta \mathrm{T}) / \Delta \mathrm{T}$

em que,

$\Delta \mathrm{TM}$ - diferença máxima diária de temperatura entre as duas sondas, ${ }^{\circ} \mathrm{C}, \mathrm{e}$

$\Delta \mathrm{T}$ - diferença de temperatura $\left({ }^{\circ} \mathrm{C}\right)$ no momento da medida, ou seja, a registrada a cada 20 minutos.

Devido à mudança no valor de $\mathrm{K}$, por causa de variações das condições térmicas do microclima, o valor de $\Delta \mathrm{TM}$ teve de ser obtido para cada dia, e, inclusive, o valor de $\mathrm{K}$ teve de ser corrigido, subtraindo dele o gradiente térmico natural (GTN) obtido no mesmo intervalo de tempo.

$\mathrm{O}$ valor de AS foi considerado igual à área da secção reta do caule/ramo no segmento aquecido, obtido por meio da medida do perímetro, menos a área ocupada pela casca, a qual foi determinada após ser extraída com estilete.

Para quantificar o GTN, foram instalados sensores sem aquecimento em plantas com tamanhos similares às dos lisímetros, para que os valores do GTN acusados nessas plantas pudessem ser transpostas às dos lisímetros. Essa operação foi feita por causa do pequeno tamanho das plantas envolvidas no experimento que não comportaram a instalação de dois pares de sensores no mesmo caule. Para obter os valores corrigidos dos fatores térmicos (Kcor), o GTN acusado simultaneamente (i) é subtraído algebricamente da medida térmica registrada pelo sensor, conforme eq.(3):

$$
\text { Kcor }=[(\Delta \mathrm{TM}-\mathrm{GTNi})-(\Delta \mathrm{T}-\mathrm{GTNi})] /(\Delta \mathrm{T}-\mathrm{GTNi})
$$

\section{RESULTADOS E DISCUSSÃO}

Na Figura 2, visualiza-se a variação ao longo de dois dias, dos valores diferenciais entre a sonda aquecida e a não-aquecida de um sensor instalado em uma das plantas do lisímetro e do gradiente térmico natural (GTN), medido em uma das plantas de controle, com sonda sem aquecimento. É apresentada, também, a curva do gradiente corrigido, obtida por meio da eq.(3). As diferenças entre os valores corrigidos e não-corrigidos são realmente contrastantes. DO \& ROCHETEAU (2002) indicam que tal gradiente pode induzir a até $100 \%$ de erro. Neste caso, na escala diária, essa interferência acarretou, em média, subestimativa do fluxo de seiva de $59 \%$ na planta 1 e de 64\% na planta 2. Os autores tinham indicado que o GTN apresentava valores negativos durante o dia e positivos durante a noite; no entanto, tal como se observa na Figura 2, neste caso, o comportamento foi o contrário.

A evolução da taxa de fluxo de seiva e da taxa de transpiração mostrou defasagem temporal com relação à taxa de evapotranspiração de referência - ETo (Figura 3). Tal defasagem, também observada por alguns autores como GRANIER (1985) e VALANCOGNE \& NASR (1989), é compreensível, pois, tanto a taxa de fluxo de seiva como a da transpiração não acompanham, no tempo, exatamente a demanda atmosférica, em função da resistência hidráulica encontrada nas plantas (ANGELOCCI, 2002). Em plantas de grande porte, segundo alguns autores (STEINBERG et al., 1989; VALANCOGNE \& NASR, 1989; WEIBEL \& VOS, 1994; HERZOG et al., 1997), ainda é comum observar defasagem temporal do fluxo de seiva com relação à transpiração, pois, em condições hídricas normais da planta, o fluxo de água na fase gasosa (transpiração) acompanha a demanda evaporativa da atmosfera. Neste caso, tratando-se de plantas jovens, tal defasagem, tão comumente observada em plantas adultas, foi pouco marcante. Porém, comparada com a demanda evaporativa da atmosfera, representada pela evapotranspiração de referência (ETo), observou-se claramente tal defasagem temporal. 


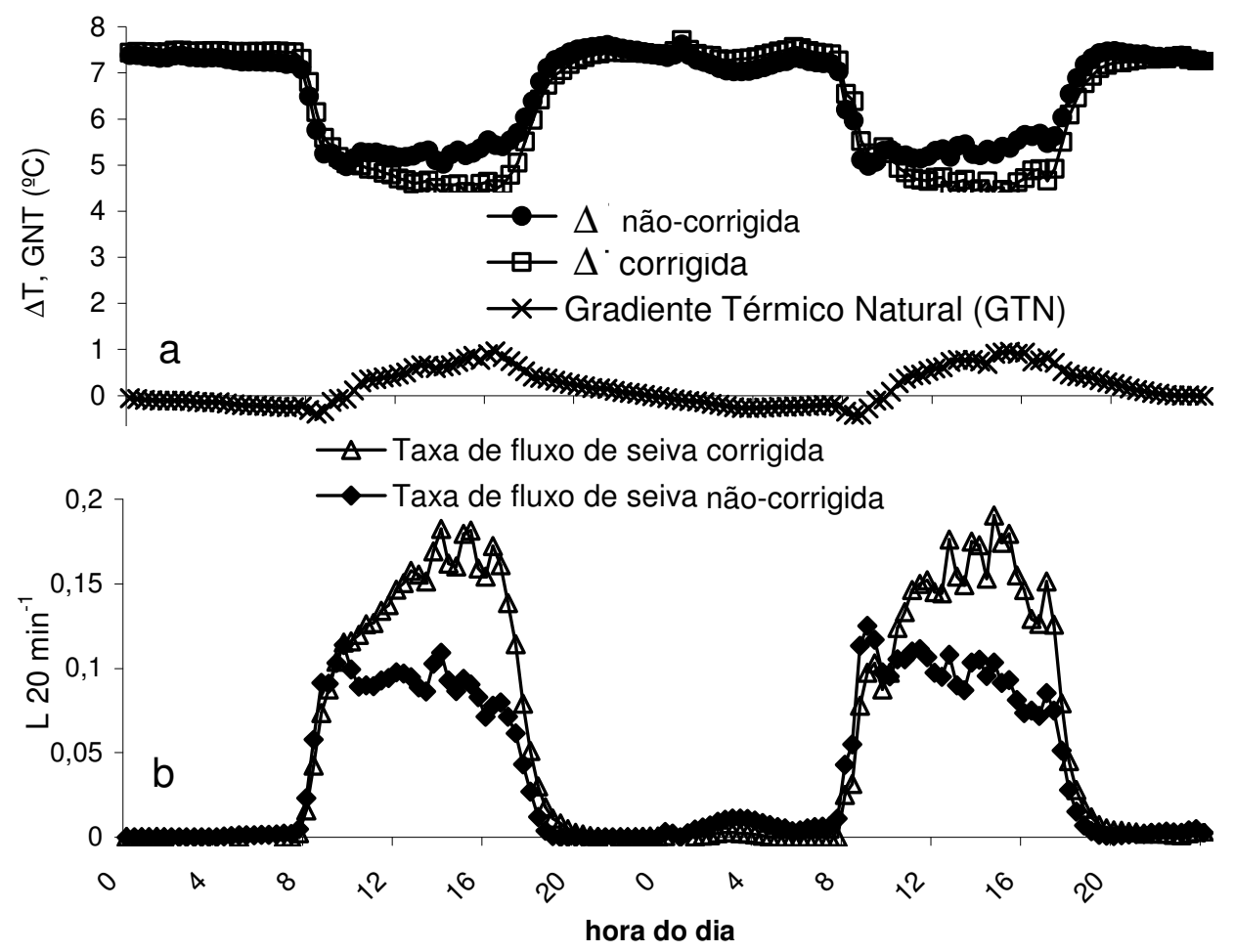

FIGURA 2. a) Gradiente térmico (Tc-Tb), gradiente térmico corrigido e gradiente térmico natural do caule; b) Variação da medida do fluxo de seiva (corrigido e não-corrigido) em planta jovem, com 3,12 $\mathrm{m}^{2}$ de área foliar, nos dias 21 e 22 de agosto de 2002.

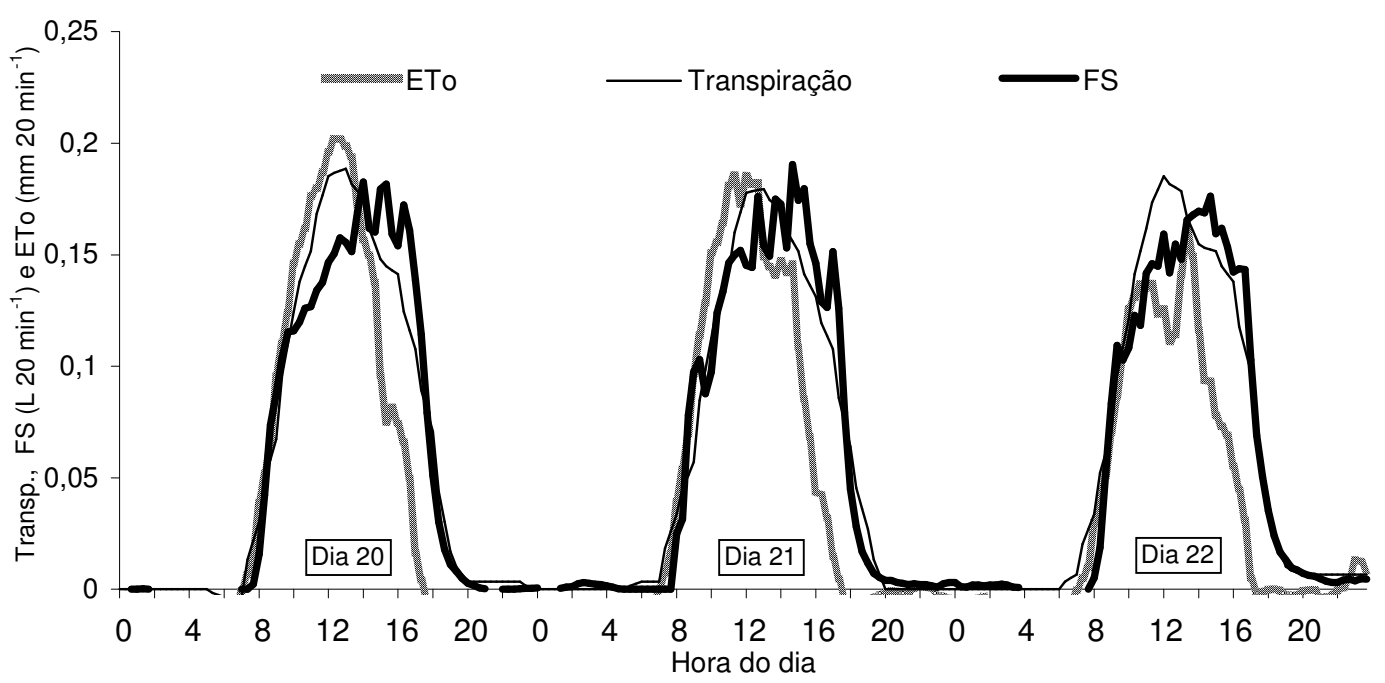

FIGURA 3. Variação da taxa de transpiração e da taxa de fluxo de seiva (FS) de uma planta com $1,78 \mathrm{~m}^{2}$ de área foliar com relação à taxa de evapotranspiração potencial (ETo), durante os dias 20; 21 e 22-8-2002.

O fluxo de seiva corrigido, totalizado para 24 horas, apresenta valores bastante concordantes com os da transpiração medida pelos lisímetros (Figura 4).

Observa-se que, apesar de os dados apresentarem certa dispersão com relação à linha de tendência, eles estão próximos à linha 1:1, o que demonstra bastante coerência, verificando-se subestimativas de apenas $3 \%$ em ambos os casos. 


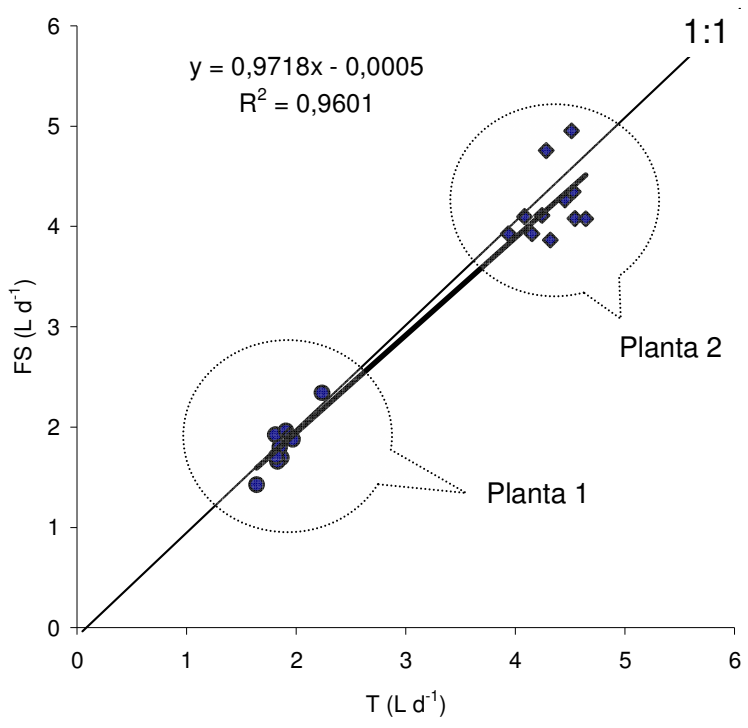

FIGURA 4. Relação entre a transpiração - T (medida por meio de lisímetros de pesagem) e o fluxo de seiva - FS (determinado pelo método de SDT). Os dados correspondem às medidas realizadas entre os dias 17 e 28-8-2002. Planta $1 \mathrm{com} 1,78 \mathrm{~m}^{2}$ de área foliar e planta 2 com $3,18 \mathrm{~m}^{2}$ de área foliar.

Exceto por alguns autores, como DAVID et al. (1997), que utilizaram esse método com eucaliptos em Portugal, HUBBARD et al. (2004) com eucalipto em Havaí, NAVES-BARBIERO et al. (2000) com espécies arbóreas do cerrado brasileiro e LU et al. (2002) com bananeira na Austrália, poucos estudos têm sido realizados utilizando essa técnica com espécies de plantas tropicais. Porém, as vantagens mencionadas anteriormente justificam que ela seja mais estudada com tais espécies, principalmente no que diz respeito às principais fontes de erros. Os resultados obtidos no presente estudo corroboram a possibilidade de utilização dessa técnica de forma segura com espécies cítricas.

O erro ocasionado pelo gradiente térmico natural, observado no presente trabalho, é bastante considerável. Conforme DO \& ROCHETEAU (2002), esse erro pode ser acentuado ainda pela combinação de certos fatores, como o tamanho do caule, a intensidade da radiação solar sobre o caule e o baixo fluxo de seiva devido ao estresse hídrico.

Por outro lado, apesar de alguns autores, como CABIBEL \& DO (1991) e KÖSTNER et al. (1998), obterem, em laboratório, equações de calibração semelhantes à de GRANIER (1985), não é garantido que as mesmas possam servir para plantas tropicais, vendo-se, portanto, a necessidade de se realizarem localmente calibrações com plantas de interesse agrícola para o País.

Outro erro pode ser atribuído à própria equação universal [eq.(2)] devido ao fato de a mesma assumir que, durante a noite, principalmente na madrugada, quando a medida de Tc-Tb é máxima, o fluxo de seiva é nulo. No entanto, pode ser que a ocorrência de fluxo nulo não seja verdadeira, já que isso depende da condição hídrica do solo, do tamanho da planta e da época do ano. Os dados de fluxo noturno encontrados na literatura são pouco informativos e de difícil comparação por terem sido obtidos sob outras condições climáticas, de espécie e de tamanho da planta, em relação às do presente trabalho. Porém, GREEN \& CLOTHIER (1988), trabalhando com kiwi (diâmetro aproximado de $60 \mathrm{~mm}$ ) e macieira (diâmetro de $82 \mathrm{~mm}$ ), encontraram, no verão, fluxo de seiva noturno, determinado por um terceiro método térmico (pulso de calor), representando, respectivamente, para cada espécie, $19 \%$ e $6 \%$ do fluxo diário médio, para 15 dias de verão na Nova Zelândia. BENYON (1999) encontrou em 24 dias de inverno na Austrália, valor médio de fluxo noturno de seiva determinado pelo método de pulso de calor equivalente a $5 \%$ da transpiração total diária.

CLEARWATER et al. (1999) discutem também erros dessa técnica de medida relacionados aos desvios na calibração universal usada, decorrentes do fato de que parte da sonda medidora pode 
ficar, na sua instalação no caule, em contato com o xilema não-condutor. Esses autores ressaltam, além disso, como principal fonte de erro, a determinação da área efetiva de fluxo de seiva. No caso deste trabalho, por serem plantas jovens, assumiu-se a área condutora de seiva como sendo toda a área da seção reta do caule, sem a casca, o que facilita as medidas. Entretanto, não se pode assegurar que, para outras condições de crescimento das plantas, essa aproximação possa ser usada.

Em síntese, esta análise qualitativa e quantitativa dos resultados demonstra que o método é suficientemente confiável desde que se monitore e se corrija o erro ocasionado pelo GTN. Sendo assim, acredita-se que futuros estudos que envolvam outras fontes de erro e aspectos técnicos de medida (registro e tratamento de dados), podem facilitar o seu uso massivo, tirando-o do ambiente acadêmico e permitindo sua utilização em meios rurais para fins de manejo da irrigação de pomares.

\section{CONCLUSÕES}

O gradiente térmico natural interfere significativamente sobre a estimativa da transpiração de planta jovem de lima ácida 'Tahiti' pela sonda de dissipação térmica.

Os valores diários $(24 \mathrm{~h})$ de fluxo de seiva determinados em plantas jovens de lima ácida 'Tahiti' pelo método da sonda de dissipação térmica mostraram-se bem concordantes com os da transpiração medida em lisímetro de pesagem, desde que feita a correção do erro ocasionado pela ocorrência de gradientes térmicos naturais no caule.

\section{REFERÊNCIAS}

ALLEN, R.G.; PEREIRA, L.S.; RAES, D.; SMITH, M. Crop evapotranspiration: guidelines for computing crop water requirements. FAO: Rome, 1998, 300 p. (Irrigation and Drainage, Paper 56).

ANGELOCCI, L.R. A planta e trocas gasosas/energéticas com a atmosfera: introdução ao tratamento biofísico. Piracicaba: Luiz Roberto Angelocci, 2002. 268 p.

ANGELOCCI, L.R.; VALANCOGNE, C. Leaf area and water flux in apple trees. Journal of Horticultural Science, London, v.68, n.2, p.299-307, 1993.

BAKER, J.M.; NIEBER, J.L. An analysis of the steady-state heat balance method for measuring sap flow in plants. Agricultural Forestry Meteorology, Amsterdam, v.48, n.1, p.93-109, 1989.

BENYON, G.B. Nighttime water use in an irrigated Eucalyptus grandis plantation. Tree Physiology, Victória, v.19, n.13, p.853-9, 1999.

BURGESS, S.S.O.; ADAMS, M.A.; TURNER, N.C.; WHITE, D.A.; ONG, C.K. Tree roots: conduits for deep recharge of soil water. Oecologia, Berlin, v.126, n.2, p.158-65, 2001.

CABIBEL, B.; DO, F. Mesures thermiques des flux de sève dans les troncs et les racines et fonctionnement hydrique des arbres: I. Analyse théorique des ereurs sur la mesure des flux et validation des mesures en présence de gradients thermiques extérieurs. Agronomie, Paris, v.11, n.8, p.669-78, 1991.

CAMPECHE, L.F.S.M.; FOLEGATTI, M.V.; NOVA, N.A.V.; COELHO FILHO, M.A.; PEREIRA, A.R. Calibração e análise de desempenho de quatro lisímetros de pesagem baseados em células de carga. In: CONGRESSO BRASILEIRO DE ENGENHARIA AGRÍCOLA, 31., 2002, Salvador. Anais... Salvador: Sociedade Brasileira de Engenharia Agrícola, 2002. 1 CD-ROM.

CERMAK, J.; DEML, M.; PENKA, M. A new method of sap flow rate determination in tress. Biologia Plantarum, Praga, v.15, p.171-8, 1973.

CLEARWATER, M.J.; MAINZER, F.C.; ANDRADE, J.L. Potential errors in measurement of no uniform sap flow using heat dissipation probes. Tree Physiology, Victória, v.19, n.2, p.681-7, 1999.

COHEN, Y.; FUCHS, M.; GREEN, G.C. Improvement of the heat pulse method for determining sap flow in trees. Pant, Cell and Environment, Blackwell, v.4, n.1, p.391-7, 1981. 
DAVID, T.S.; FERREIRA, D.J.S.; PEREIRA, J.S. Transpiration from a mature Eucalyptus globulus plantation in Portugal during a spring-summer period of progressively higher water deficit. Oecologia, Berlin, v.110, n.2, p.153-9, 1997.

DELGADO-ROJAS, J.S. Avaliação do uso do fluxo de seiva e da variação do diâmetro do caule e de ramos na determinação das condições hídricas de citros, como base para o manejo de irrigação. 2003. 110 f. Tese (Doutorado em Irrigação e Drenagem) - Escola Superior de Agricultura "Luiz de Queiroz”, Universidade de São Paulo, Piracicaba, 2003.

DO, F.; ROCHETEAU, A. Influence of natural temperature gradients on measurements of xylem sap flow with thermal dissipation probes. 1. Field observations and possible remedies. Tree Physiology, Victória, v.22, n.1, p.641-8, 2002.

FERREIRA, M. I.; ZITSCHER, H. Measurements performed with Granier method in short trunks near the soil. In: WORKSHOP ON MEASURING SAP FLOW IN INTACT PLANT, 3., 1996, Barcelona. Proceedings...Barcelona: Sitges, 1996. p.1-3.

GIORIO, P.; GIORIO, G. Sap flow of several olive trees estimated with the heat-pulse technique by continuous monitoring of a single gauge. Environmental and Experimental Botany, Amsterdam, v.49, n.1, p.9-20, 2003.

GRANIER, A. Une nouvelle méthode pour la mesure du flux de sève brute dans le tronc des arbres. Annales des Sciences Foresties, Versailles, v.42, n.2, p.193-200, 1985.

GRANIER, A. Mesure du flux de sève brute dans le tronc du douglas par une nouvelle méthode thermique. Annales Des Sciences Forestières, Versailles, v.44, n.1, p.1-14, 1987.

GRANIER, A.; BRÉDA, N. Modeling canopy conductance and stand transpiration of an oak forest from sap flow measurements. Annales des Sciences Forestières, Versailles, v.53, n.1, p.537-46, 1996.

GREEN, S.R.; CLOTHIER, B.E. Water use of kiwifruit vines and apples trees by the heat-pulse technique. Journal of Experimental Botany, Oxford, v.39, n.1, p.115-23, 1988.

HERZOG, K.M.; THUM, R.; SWEIFEL, R.; HASLER, R. Heat balance measurements - to quantify sap flow in thin stems only. Agricultural and Forest Meteorology, Amsterdam, v.83, n.1, p.75-94, 1997.

HUBBARD, R.M.; RYAN, M.G.; GIARDINA, C.P.; BARNARD, H. The effect of fertilization on sap flux and canopy conductance in a Eucalyptus saligna experimental forest. Global Change Biology, Colorado, v.10, n.4, p.427-36, 2004.

KÖSTNER, B.; GRANIER, A.; CERMÁK, J. Sapflow measurements in forest stands: methods and uncertainties. Annuary Science Foresty, Paris, v.55, n.1, p.13-27, 1998.

LOUSTAU, D.; DOMEC, J.C.; BOSC, A. Interpreting the variations in xylem sap flux density within the trunk of maritime pine (Pinus pinaster Ait.): application of a model for calculating water flows at tree and stand levels. Annales des Sciences Forestieres, Versailles, v.55, n.1, p.29-40, 1998.

LU, P.; WOO, K.; LIU, Z. Estimation of whole-plant transpiration of bananas using Sap flow measurements. Journal of Experimental Botany, Oxford, v.53, n.375, p.1771-9, 2002.

LUNDBLAD, M.; LAGERGREN, F.; LINDROTH, A. Evaluation of heat balance and heat dissipation methods for sapflow measurements in pine and spruce. Annales des Sciences Forestierès, Versailles, v.58, n.6, p. 625-38, 2001.

NAVES-BARBIERO, C.C.; FRANCO, A.C.; BUCCI, S.J.; GOLDSTEIN, G. Fluxo de seiva e condutância estomática de duas espécies lenhosas sempre-verdes no campo sujo e cerradão. Revista Brasileira de Fisiologia Vegetal, Campinas, v.12, n.2, p.119-34, 2000. 
SAKURATANI, T. A heat balance method for measuring water flux in the stem of intact plants. Journal of Agricultural Meteorology, Amsterdam, v.37, n.1, p.9-17, 1981.

SMITH, D.M.; ALLEN, S.J. Measurement of sap flow in plants stems. Journal of Experimental Botany, Lancaster, v.47, n.305, p.1833-44, 1996.

STEINBERG, S.L.; BAVEL, C.H.M.Van; McFARLAND, M. A gauge to measure mass flow rate of sap in stems and trunks of woody plants. Journal of the American Society for Horticultural Science, Alexandria, v.114, n.3, p.466-72, 1989.

TATARINOV, F.; KUCERA, J.; CIENCIALA, E. The analysis of physical background of tree sap flow measurement based on thermal methods. Measurement Science Technology, London, v.16, n.1, p.1157-69, 2005.

TOURNEBIZE, R.; BOISTARD, S. Comparison of two sap flow methods for the estimation of tree transpiration. Annales des Sciences Forestieres, Versailles, v.55, n.6, p.706-13, 1998.

VALANCOGNE, C.; NASR, Z. Une methode de mesure du débit de séve brute dans des petits arbres par bilan de chaleur. Agronomie, Paris, v.9, n.6, p.609-17, 1989.

WEIBEL, F.P.; de VOS, J.A. Transpiration measurements in apple trees: an improved stem balance heat method. Plant and Soil, Springer, v.166, n.2, p.203-17, 1994. 